\title{
The effect of ultrafiltration transmembrane permeation on the flow field in a surrogate system of an artificial kidney
}

\author{
Matilde De Pascale ${ }^{3}$, Monica Faria ${ }^{1}$, Cristiana Boi $^{3}$, Viriato Semiao ${ }^{2}$ (D) and \\ Maria Norberta de Pinho ${ }^{1, *}$ \\ ${ }^{1}$ CeFEMA, Department of Chemical Engineering Instituto Superior Técnico, Universidade de Lisboa, Lisboa, Portugal, \\ ${ }^{2}$ IDMEC, Department of Mechanical Engineering Instituto Superior Técnico, Universidade de Lisboa, Lisboa, Portugal, and \\ ${ }^{3}$ Department of Civil, Chemical, Environmental and Materials Engineering (DICAM), University of Bologna, Bologna, Italy \\ *Corresponding author. E-mail: marianpinho@tecnico.ulisboa.pt
}

(Received 24 June 2020; Revised 01 March 2021; Accepted 01 March 2021)

\begin{abstract}
Renal Replacement Therapies generally associated to the Artificial Kidney (AK) are membrane-based treatments that assure the separation functions of the failing kidney in extracorporeal blood circulation. Their progress from conventional hemodialysis towards high-flux hemodialysis (HFHD) through the introduction of ultrafiltration membranes characterized by high convective permeation fluxes intensified the need of elucidating the effect of the membrane fluid removal rates on the increase of the potentially blood-traumatizing shear stresses developed adjacently to the membrane. The AK surrogate consisting of two-compartments separated by an ultrafiltration membrane is set to have water circulation in the upper chamber mimicking the blood flow rates and the membrane fluid removal rates typical of HFHD. Pressure drop mirrors the shear stresses quantification and the modification of the velocities profiles. The increase on pressure drop when comparing flows in slits with a permeable membrane and an impermeable wall is $c a$. $512 \%$ and $576 \%$ for $\mathrm{CA} 22 / 5 \% \mathrm{SiO}_{2}$ and $\mathrm{CA} 30 / 5 \% \mathrm{SiO}_{2}$ membranes, respectively.
\end{abstract}

Keywords: High-flux hemodialysis; Ultrafiltration cellulose acetate /silica hybrid membranes; Two-compartment artificial kidney surrogate; Fluid volume removal and hemodynamic management; High shear stresses in membrane/fluid interfaces

\section{Introduction}

Chronic Kidney Disease (CKD) affects 11-13\% of the world population (Hill et al., 2016) and Renal Replacement Therapies (RRTs) stand as a life support for most of these patients. The RRTs generally associated to the Artificial Kidney (AK) are membrane-based treatments which assure the separation functions of the failing kidney in extracorporeal blood circulation. In the 1990s, the progress from conventional hemodialysis (HD) controlled by diffusion and known as low-flux hemodialysis (LFHD) to new RRTs like hemofiltration(HF), hemodiafiltration (HDF) and high-flux HD (HFHD) (Cheung et al., 2003) was due to the introduction of ultrafiltration (UF) membranes characterized by high convective permeation fluxes. Despite the advancement on the efficient removal of small water-soluble toxins and slight improvement on the removal of middle size molecules and protein bound uremic toxins (Vanholder et al., 2003), fluid volume removal and hemodynamic management remains as a matter of concern due to its association to cardiovascular stress and potential organ damage (Canaud et al., 2019; Poorkhalil et al., 2019).

\footnotetext{
(c) The Author(s), 2021. Published by Cambridge University Press. This is an Open Access article, distributed under the terms of the Creative Commons Attribution licence (http://creativecommons.org/licenses/by/4.0/), which permits unrestricted re-use, distribution and reproduction, provided the original article is properly cited.
} 


\section{Objective}

Despite the understanding of hemodynamics as being directly dependent on fluid mechanics fundamentals, little attention has been given to the main focus of the present work, which is the influence of the fluid removal rates typical of HFHD on the flow field, particularly on the increase of the potentially blood-traumatizing shear stresses developed adjacently to the membrane. In fully developed flow, as the slit flow case herein, the pressure drop mirrors the magnitude of the forces responsible for the shear stresses near the wall and its quantification is performed in a surrogate system of an $\mathrm{AK} / \mathrm{hemodialyzer}$ mimicking tangential fluid velocities and membrane removal rates with circulating water.

\section{Methods}

Two flat-sheet laboratory-made ultrafiltration (UF) hybrid membranes of cellulose acetate(CA)/silica $\left(\mathrm{SiO}_{2}\right)$ are tested. The synthesis and characterization (SEM, ATR/FTIR, NMR) of CA30/5\% $\mathrm{SiO}_{2}$ and $\mathrm{CA} 22 / 5 \% \mathrm{SiO}_{2}$ was previously reported by Mendes et al. (2018) (membrane A5) and Beira et al. (2019), respectively. Figure 1 (a) shows the experimental setup, comprising the two-compartment AK surrogate where the semi-permeable membrane (surface area of $0.0021 \mathrm{~m}^{2}$ ) separates the top slit (height, $\mathrm{h}=600 \mu \mathrm{m} \ll$ width, $\mathrm{W}=3 \mathrm{~cm}$ - Figure 1 (b)) for feed circulation from the bottom chamber receiving the membrane permeating fluid. The feed/water $\left(\mathrm{T}=37^{\circ} \mathrm{C}\right)$ pumped through the slit at volumetric flowrates $40 \mathrm{ml} / \mathrm{min} \leq \mathrm{Q} \leq 160 \mathrm{~mL} / \mathrm{min}$ generates pressure drops, $\Delta P=\mathrm{PT} 1-\mathrm{PT} 2$, along length $\mathrm{L}=25 \mathrm{~cm}$, registered for permeable and impermeable walls. The $\Delta P$ uncertainty, $\sigma_{\Delta P}= \pm 20 \%$, depends on the pressure sensors precision (high accuracy: $\pm 1.33 \times 10^{2} \mathrm{~Pa}$ ) and, mainly, on both the slit height and local pressure losses uncertainties (estimated through literature empirical correlations). Pressure sensors are computer connected through the data acquisition program LabVIEW. Transmembrane pressure ranges from $3 \times 10^{3} \mathrm{~Pa}$ to $1.5 \times 10^{4} \mathrm{~Pa}$. A fully-developed laminar flow of a Newtonian-fluid (dynamic viscosity $\mu$ ) inside a slit, with hydrodynamic smooth-surfaces, experiences the pressure reduction $\Delta P_{\text {th }}=12 \frac{\mu L Q}{W h^{3}\left[1-0.63 \frac{h}{W}\right]}$ (Bruus, 2008), with uncertainty $\sigma_{\Delta P}= \pm 18 \%$ depending on the intervening variables uncertainties (Miller \& Miller, 1993). These theoretical values are compared with the experimental ones.

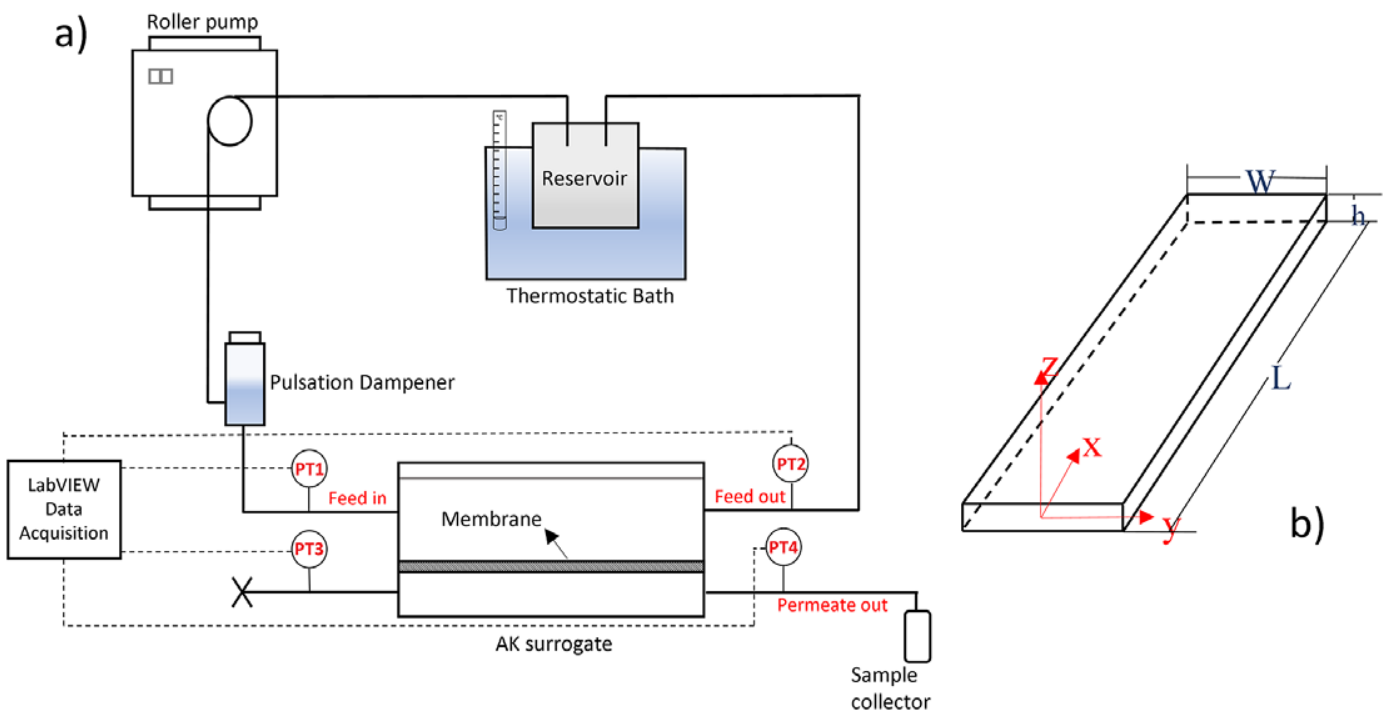

Figure 1. (a) Experimental setup. (b) Top slit geometry and coordinate axis. 


\section{Results and discussion}

The hydraulic permeability of the membranes is $18.09 \mathrm{~kg} / \mathrm{h} / \mathrm{m}^{2} / \mathrm{bar}$ for CA22/5\% $\% \mathrm{SiO}_{2}$ and $198.65 \mathrm{~kg} / \mathrm{h} /$ $\mathrm{m}^{2} /$ bar for $\mathrm{CA} 30 / 5 \% \mathrm{SiO}_{2}$.

All figures ahead display pressure drop $(\Delta P)$ results as a function of the volumetric flowrate $(Q)$ in the surrogate AK.

Figure 2 compares theoretical and experimental results without permeation. Linear dependence of $\Delta P$ on $Q$, with a slope increase with the channel height reduction (compare red and black lines), confirms the laminar regime of a fully developed Poiseuille-type flow (Silva et al., 2008). The much larger experimental $\Delta P$ values (relatively to the theoretical ones: compare red and blue lines) emerge from the walls roughness. This can be modelled by an apparent viscosity (Magueijo et al., 2006).

Figure 3 illustrates in HFHD the effect of membrane removal rates on the slit flow field. Both experimental $\Delta P$ lines with permeation exhibit consistently much larger slopes than the theoretical one (compare green and red lines against black line), evidencing the increase of potentially bloodtraumatizing shear stresses at the membrane surface. Such enormous increase (ca. 512\% for CA22/5\% $\mathrm{SiO}_{2}$ and $576 \%$ for $\mathrm{CA} 30 / 5 \% \mathrm{SiO}_{2}$ membrane) is probably due to the high removal rates, which deform the velocity profile shifting its maximum towards the lower-half slit and, hence, increasing the velocity gradient at the membrane surface: the fully developed flow condition may be at stake. Moreover, $\Delta P$ line for membrane $\mathrm{CA} 22 / 5 \% \mathrm{SiO}_{2}$ exhibits a slope smaller than that $\mathrm{CA} 30 / 5 \% \mathrm{SiO}_{2}$ (compare green line with red line). This is in accordance with the fact that the $\mathrm{CA} 22 / 5 \% \mathrm{SiO}_{2}$ is a smoother membrane.

Taking into consideration that the $\mathrm{CA} 30 / 5 \% \mathrm{SiO}_{2}$ membrane complies with the kidney metabolic functions of preferential permeation of urea and retention of albumin (Faria et al., 2020), Figure 4 shows the results of $\triangle P v s . Q$ for the solutions of these two solutes and other typical toxins at different concentrations/different viscosities. Within the range of the experimental error, there is no significant effect of the solutions viscosity on $\Delta P$ (all experimental points are around the black line for water).

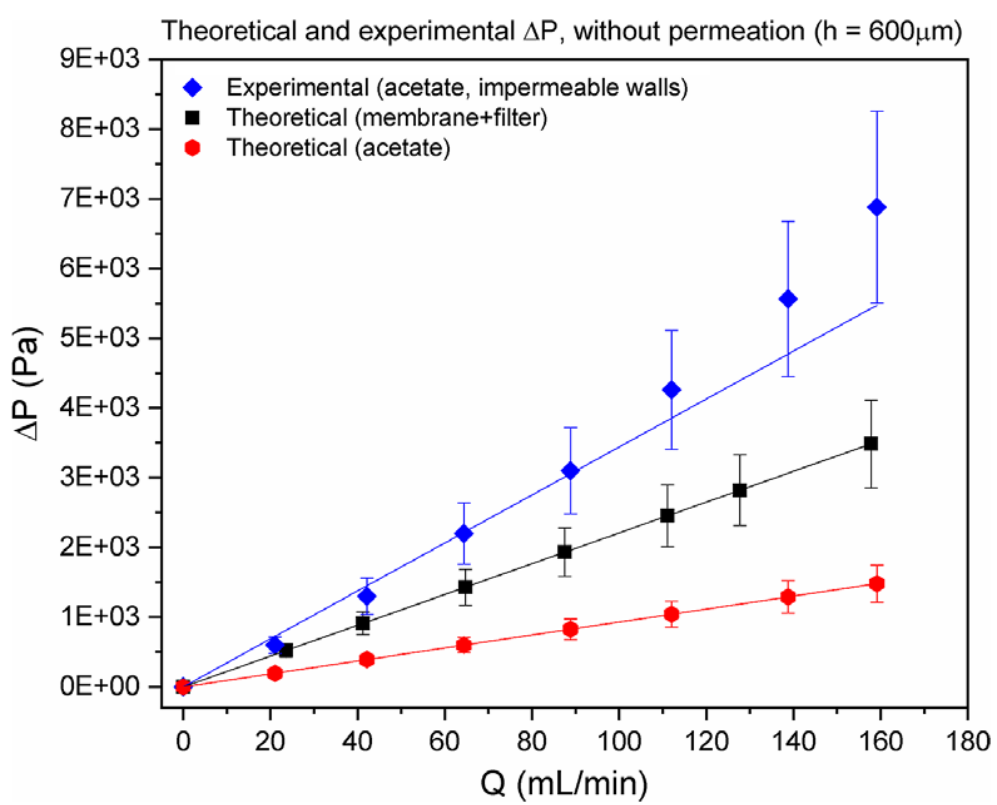

Figure 2. Theoretical and experimental pressure drop, $\Delta P$, in an impermeable surrogate system of a hemodialyzer as a function of the volumetric flow rate, $Q$. Red line refers to theoretical pressure drop in the slit with an acetate at the bottom wall (without permeation). Black line refers to theoretical pressure drop in the slit with a membrane over a filter paper at the bottom wall (without permeation). Blue line refers to the experimental pressure drop in a slit with an acetate at the impermeable bottom wall. 


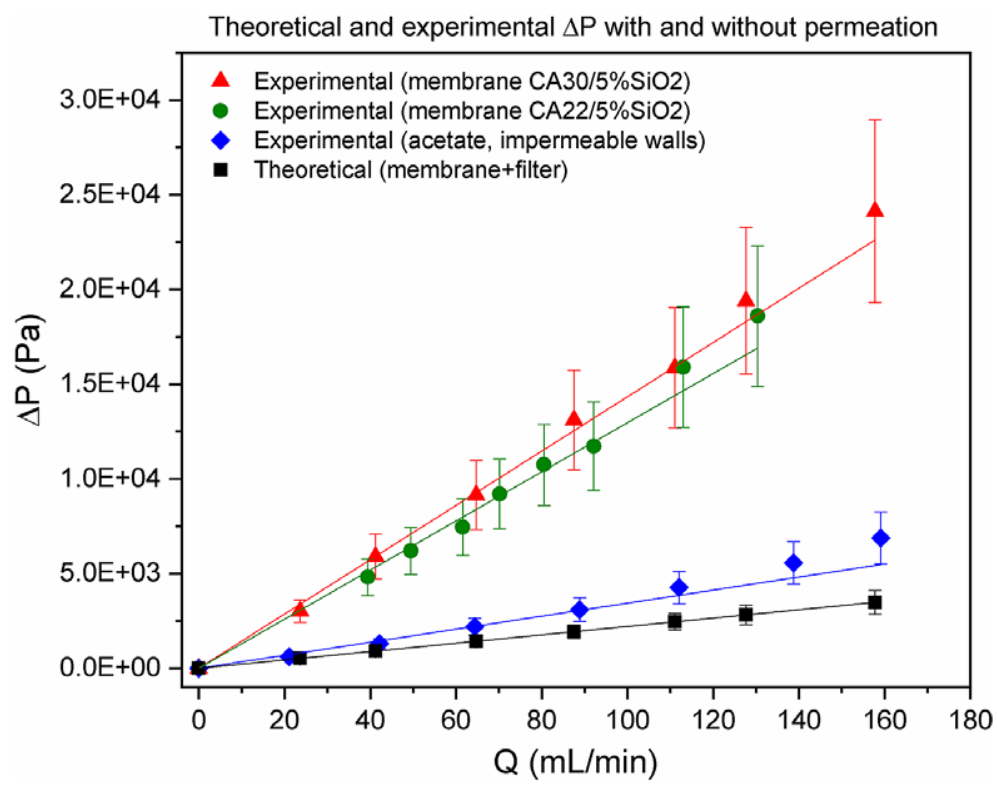

Figure 3. Theoretical and experimental pressure drop, $\Delta P$, in a surrogate system of a hemodialyzer as a function of the volumetric flow rate, $Q$. Black line refers to the theoretical pressure drop in a slit with a membrane over a filter paper at the bottom wall (without permeation). Blue line refers to the experimental pressure drop in a slit with an acetate at the bottom wall (without permeation). Green and red lines refer to the experimental pressure drop in a slit with permeation (bottom wall with $\mathrm{CA} 30 / 5 \% \mathrm{SiO}_{2}$ membrane for the red line and $\mathrm{CA} 22 / 5 \% \mathrm{SiO}_{2}$ membrane for the green line).

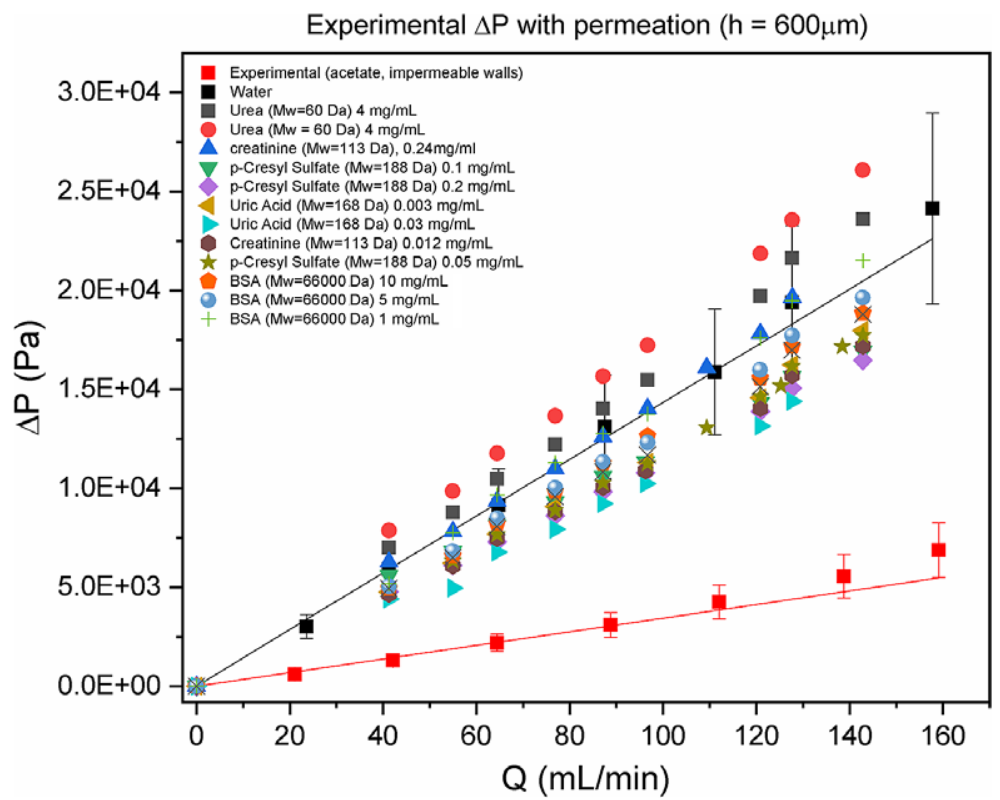

Figure 4. Experimental pressure drop, $\triangle P$, with permeation of pure water and solutions of toxins \& bovine serum albumin (BSA) in a surrogate system of a hemodialyzer as a function of the volumetric flow rate, $Q$, with membrane $\mathrm{CA} 30 / 5 \% \mathrm{SiO}_{2}$. $\mathrm{Black}$ line refers to the experimental pressure drop in a slit with pure water permeation. Red line is the reference for the experimental pressure drop without permeation. The solutions of the toxins (urea, creatinine, uric acid \& p-cresyl sulfate) and of the BSA have different concentrations. 


\section{Conclusion}

UF permeation experiments in HFHD typical conditions, performed in a surrogate AK/hemodialyzer, elucidated how fluid mechanics fundamentals rule the effects of high removal rates on the blood flow field. The paramount increase on pressure drop, compared to that of impermeable theoretical flow conditions, $c a .512 \%$ for membrane $\mathrm{CA} 22 / 5 \% \mathrm{SiO}_{2}$ and $576 \%$ for $\mathrm{CA} 30 / 5 \% \mathrm{SiO}_{2}$, reflects the increase on magnitude of the potentially blood-traumatizing shear stresses at the membrane surface. This comes from the distortion of the circulating fluid velocity profile, with its maximum shifted into the membrane surface direction, increasing, therefore, the velocity gradient there.

Funding Information. This work was supported by FCT, Fundação para a Ciência e Tecnologia, Portugal (through CeFEMA, Centre of Physics and Engineering Advanced Materials, UID/CTM/04540/2013 and project PTDC/CTM-BIO/6178/2014), (through IDMEC, under LAETA, project UIDB/50022/2020, IDMEC, Instituto Superior Técnico, Universidade de Lisboa, Lisboa, Portugal); and Italian Ministry of Education University and Research (Department of Civil, Chemical, Environmental and Materials Engineering, University of Bologna, Italy).

Conflict of Interest. The authors have no conflicts of interest to declare.

Data Availability Statement. Readers can contact the authors if they want access to such materials.

\section{References}

Beira, M. J., Silva, M. P., Condesso, M., Cosme, P., Almeida, P. L., Corvo, M. C., Sebastião, P. J., Figueirinhas, J. L., \& de Pinho, M. N. (2019). Molecular order and dynamics of water in hybrid cellulose acetate-silica asymmetric membranes. Molecular Physics, 117, 975-982. doi: https://doi.org/10.1080/00268976.2018.1537526.

Bruus, H. (2008). Theoretical microfluidics. Oxford University Press.

Canaud, B., Chazot, C., Koomans, J., \& Collins, A. (2019). Fluid and hemodynamic management in hemodialysis patients: Challenges and opportunities. Brazilian Journal of Nephrology, 41, 550-559. doi: https://doi.org/10.1590/2175-8239jbn-2019-0135.

Cheung, A. K., Levin, N. W., Greene, T., Agodoa, L., Bailey, J., Beck, G., Clark, W., Levey, A. S., Leypoldt, J. K., Ornt, D. B., Rocco, M. V., Schulman, G., Schwab, S., Teehan, B., \& Eknoyan, G. (2003). Effects of high-flux hemodialysis on clinical outcomes: Results of the HEMO study. Journal of the American Society of Nephrology, 14, 3251-3263. doi: https://doi. org/10.1097/01.ASN.0000096373.13406.94.

Faria, M., Moreira, C., Eusébio, T., Brogueira, P., \& de Pinho, M. N. (2020). Hybrid flat sheet cellulose acetate/silicon dioxide ultrafiltration membranes for uremic blood purification. Cellulose, 27, 3847-3869. doi:10.1007/s10570-020-02985-2.

Hill, N. R., Fatoba, S. T., Oke, J. L., Hirst, J. A., O’Callaghan, C. A., Lasserson, D. S., \& Hobbs, F. D. R. (2016). Global prevalence of chronic kidney disease - A systematic review and meta-analysis. PLoS One, 11, e0158765. doi: https://doi. org/10.1371/journal.pone.0158765.

Magueijo, V., Semiao, V., \& de Pinho, M. N. (2006). Effect of ultrafiltration permeation rates on the hydrodynamics of a minichannel/slit laminar flow. Chemical Engineering Science, 61, 7139-7150. doi:https://doi.org/10.1016/j.ces.2006.07.041.

Mendes, G., Faria, M., Carvalho, A., Gonçalves, M. C., \& de Pinho, M. N. (2018). Structure of water in hybrid cellulose acetatesilica ultrafiltration membranes and permeation properties. Carbohydrate Polymers, 189, 342-351. doi: https://doi. org/10.1016/j.carbpol.2018.02.030.

Miller, J. C., \& Miller, J. N. (1993). Statistics of analytical chemistry (3rd ed.). Prentice-Hall.

Poorkhalil, A., Mouzakis, F., Kashefi, A., \& Mottaghy, K. (2019). The course of hematocrit value along the length of a dialyzer's fiber: Hemoconcentration modeling and validation methods. The International Journal of Artificial Organs, 42, 482-489. doi: https://doi.org/10.1177/0391398819847214.

Silva, G., Leal, N., \& Semiao, V. (2008). Micro-PIV and CFD characterization of flows in a microchannel: velocity profiles, surface roughness and Poiseuille numbers. International Journal of Heat and Fluid Flow, 29, 1211-1220. doi: https://doi. org/10.1016/j.ijheatfluidflow.2008.03.013.

Vanholder, R., De Smet, R., Glorieux, G., Argilés, A., Baurmeister, U., Brunet, P., Clark, W., Cohen, G., De Deyn, P. P., Deppisch, R., Descamps-Latscha, B., Henle, T., Jörres, A., Lemke, H. D., Massy, Z. S., Passlick-Deetjen, J., Rodriguez, M., Stegmayr, B., Stenvinkel, P., \& European Uremic Toxin Work Group (EUTox). (2003). Review on uremic toxins: Classification, concentration and interindividual variability. Kidney International, 63, 1934-1943. doi: https://doi. org/10.1046/j.1523-1755.2003.00924.x.

Cite this article: De Pascale M, Faria M, Boi C, Semiao V, de Pinho MN (2021). The effect of ultrafiltration transmembrane permeation on the flow field in a surrogate system of an artificial kidney Experimental Results, 2, e16, 1-9. https://oi.org/ $10.1017 / \exp .2021 .5$ 


\title{
Peer Reviews
}

\author{
Reviewing editor: Dr. Mihriban O. Pekguleryuz
}

McGill University, Montreal, Quebec, Canada, H3A 0G4

This article has been accepted because it is deemed to be scientifically sound, has the correct controls, has appropriate methodology and is statistically valid, and has been sent for additional statistical evaluation and met required revisions.

\section{doi:10.1017/exp.2021.5.pr1}

\section{Review 1: The effect of ultrafiltration transmembrane permeation on the flow field in a surrogate system of an artificial kidney}

Reviewer: Dr. Loredana De Bartolo

Date of review: 05 October 2020

(C) The Author(s), 2021. Published by Cambridge University Press. This is an Open Access article, distributed under the terms of the Creative Commons Attribution licence (http://creativecommons.org/licenses/by/4.0/), which permits unrestricted re-use, distribution and reproduction, provided the original article is properly cited.

Conflict of interest statement. Reviewer declares none

Comments to the Author: The authors focused the manuscript on the effect of ultrafiltration transmembrane permation on the flow field by using a surrogate system of a hemodialyzer. They tested two flatsheet laboratory-made hybrid membranes of cellulose acetate(CA)/silica $\left(\mathrm{SiO}_{2}\right): \mathrm{CA} 30 / 5 \% \mathrm{SiO}_{2}$ and $\mathrm{CA} 22 / 5 \% \mathrm{SiO}_{2}$.

The experimental results are interesting and I suggest to revise the manuscript in order to clarify some minor issues.

1) The Authors should include in the manuscript information about the membranes used in this study (e.g., pore size, porosity, thickness, physico-chemical, etc.) in order to provide to readers a comprehensive view of the membrane characteristics and to appreciate the differences with other suitable commercial membranes.

2) A more detailed description and discussion for Figure 4 would be more appropriate.

\section{Score Card}

Presentation

3.3

Is the article written in clear and proper English? (30\%)

Is the data presented in the most useful manner? (40\%)

Does the paper cite relevant and related articles appropriately? (30\%) 
Does the abstract correctly embody the content of the article? (25\%)

Does the introduction give appropriate context? (25\%)

Is the objective of the experiment clearly defined? (25\%)

Analysis

Does the discussion adequately interpret the results presented? (40\%)

Is the conclusion consistent with the results and discussion? (40\%)

Are the limitations of the experiment as well as the contributions of the experiment clearly outlined? $(20 \%)$ 


\section{Review 2: The effect of ultrafiltration transmembrane permeation on the flow field in a surrogate system of an artificial kidney}

Reviewer: Prof. Margit Gföhler

Date of review: 21 January 2021

(C) The Author(s), 2021. Published by Cambridge University Press. This is an Open Access article, distributed under the terms of the Creative Commons Attribution licence (http://creativecommons.org/licenses/by/4.0/), which permits unrestricted re-use, distribution and reproduction, provided the original article is properly cited.

Conflict of interest statement. reviewer declares none

Comments to the Author: The article is very interesting and timely, as it addresses an important topic in the development of artificial kidney devices with improved characteristics.

\section{Minor comments:}

Lines 49-50: ,pressure drop mirrors the magnitude of such forces', please explain more clearly what is the relation here (maybe add a reference?), and maybe replace 'such forces' by ' forces due to these shear stresses' or similar.

Line 57: 'designation of ...' is not clear

Line 63: should be ...Q $<=160 \mathrm{ml} / \mathrm{min}$ ?

Three different units of measure are used for pressure $-\mathrm{mmHg}$, bar, Pa. This is confusing, please convert to only one unit for measure throughout the paper for consistency.

Figure 3: Hydraulic permeability of the two used membranes is very different (factor 10), leading only to a small difference in the flow-pressure curves. The authors state that this might be attributed to similar surface roughness (line 95). It would be interesting here to at least roughly indicate how much of the total difference acetate - membrane can be attributed to roughness and how much to removal rates, as this is important for the addressed research question.

\section{Score Card}

Presentation

Does the paper cite relevant and related articles appropriately? (30\%) 
Are the limitations of the experiment as well as the contributions of the experiment clearly outlined? (20\%) 